\title{
Contemporary Ventilator Management in Patients With and at Risk of ALI/ARDS
}

\author{
Steven Y Chang MD PhD, Ousama Dabbagh MD, Ognen Gajic MD, \\ Amee Patrawalla MD MPH, Marie-Carmelle Elie MD, Daniel S Talmor MD MPH, \\ Atul Malhotra MD, Adebola Adesanya MD MPH, Harry L Anderson III MD, James M Blum MD, \\ Pauline K Park MD, and Michelle Ng Gong MD MSc, on behalf of the United States Critical \\ Illness and Injury Trials Group: Lung Injury Prevention Study Investigators (USCIITG-LIPS)
}

\begin{abstract}
BACKGROUND: Ventilator practices in patients at risk for acute lung injury (ALI) and ARDS are unclear. We examined factors associated with choice of set tidal volumes $\left(\mathrm{V}_{\mathrm{T}}\right)$, and whether $\mathrm{V}_{\mathrm{T}}<8 \mathrm{~mL} / \mathrm{kg}$ predicted body weight (PBW) relates to the development of ALI/ARDS. METHODS: We performed a secondary analysis of a multicenter cohort of adult subjects at risk of lung injury with and without ALI/ARDS at onset of invasive ventilation. Descriptive statistics were used to describe ventilator practices in specific settings and ALI/ARDS risk groups. Logistic regression analysis was used to determine the factors associated with the use of $V_{T}<8 \mathrm{~mL} / \mathrm{kg} \mathrm{PBW}$ and the relationship of $V_{T}$ to ALI/ARDS development and outcome. RESULTS: Of 829 mechanically ventilated patients, 107 met the criteria for ALI/ARDS at time of intubation, and 161 developed ALI/ARDS after intubation (post-intubation ALI/ARDS). There was significant intercenter variability in initial ventilator settings, and in the incidence of ALI/ARDS and post-intubation ALI/ ARDS. The median $V_{T}$ was 7.96 (IQR 7.14-8.94) $\mathrm{mL} / \mathrm{kg}$ PBW in ALI/ARDS subjects, and 8.45 (IQR 7.50-9.55) $\mathrm{mL} / \mathrm{kg}$ PBW in subjects without ALI/ARDS $(P=.004) . V_{T}$ decreased from 8.40 (IQR 7.38-9.37) $\mathrm{mL} / \mathrm{kg}$ PBW to 7.97 (IQR 6.90-9.23) $\mathrm{mL} / \mathrm{kg}$ PBW $(P<.001)$ in those developing post-intubation ALI/ARDS. Among subjects without ALI/ARDS, $V_{T} \geq 8 \mathrm{~mL} / \mathrm{kg} P B W$ was associated with shorter height and higher body mass index, while subjects with pneumonia were less likely to get $\geq 8 \mathrm{~mL} / \mathrm{kg}$ PBW. Initial $\mathrm{V}_{\mathrm{T}} \geq 8 \mathrm{~mL} / \mathrm{kg}$ PBW was not associated with the post-intubation ALI/ARDS (adjusted odds ratio 1.30, $95 \%$ CI 0.74-2.29) or worse outcomes. Post-intubation ALI/ ARDS subjects had mortality similar to subjects intubated with ALI/ARDS. CONCLUSIONS: Clinicians seem to respond to ALI/ARDS with lower initial $V_{T}$. Initial $V_{T}$, however, was not associated with the development of post-intubation ALI/ARDS or other outcomes. (ClinicalTrials.gov registration NCT00889772) Key words: acute lung injury; ARDS; mechanical ventilation; mortality; tidal volume. [Respir Care 2013;58(4):578-588. @ 2013 Daedalus Enterprises]
\end{abstract}

\section{Introduction}

Many critically ill patients require invasive mechanical ventilation because of acute lung injury (ALI) and its more

\footnotetext{
Drs Chang and Patrawalla are affiliated with the Division of Pulmonary and Critical Care Medicine, University of Medicine and Dentistry of New Jersey, New Jersey Medical School, Newark, New Jersey. Dr Dabbagh is affiliated with the Department of Internal Medicine, University of Missouri, Columbia, Missouri. Dr Gajic is affiliated with the Division of Pulmonary and Critical Care Medicine, Mayo Clinic, Rochester, Minnesota. Dr Elie is affiliated with the Department of Emergency Medicine, University of Florida, Gainesville, Florida. Dr Talmor is affiliated with
}

severe subset ARDS (ALI/ARDS-on-intubation). Patients with established ALI/ARDS benefit from lung-protective ventilation (use of low tidal volume $\left[\mathrm{V}_{\mathrm{T}}\right]$ ventilation and

the Department of Anesthesia, Critical Care and Pain Medicine, Harvard Medical School, Beth Israel Deaconess Medical Center, Boston Massachusetts. Dr Malhotra is affiliated with the Divisions of Pulmonary and Critical Care and Sleep Medicine, Harvard Medical School, Brigham and Women's Hospital, Boston Massachusetts. Dr Adesanya is affiliated with the Department of Anesthesiology and Internal Medicine, University of Texas Southwestern Medical Center, Dallas, Texas. Dr Anderson is affiliated with Trauma/Surgical Critical Care, St Joseph Mercy Hospital, Ann Arbor, Michigan. Dr Blum is affiliated with the Department of 
limitation of plateau pressure). ${ }^{1-4}$ Studies, however, have shown that adoption of low $\mathrm{V}_{\mathrm{T}}$ in ALI/ARDS, including at academic medical centers, has been variable. ${ }^{5-11}$ The approach to PEEP is even more uncertain. Despite substantial research, there is no consensus about whether PEEP higher than that used in the ARDS Network low- $\mathrm{V}_{\mathrm{T}}$ trial $^{2}$ ought to be instituted in patients with ALI/ARDS. The ALVEOLI trial demonstrated no impact of a higher PEEP strategy on mortality or morbidity. ${ }^{12}$ Neither the Lung Open Ventilation Study nor the Expiratory Pressure study showed mortality benefit to using recruitment maneuvers and higher PEEP, although other end points were positively impacted. ${ }^{13,14}$

\section{See the Related Editorial on Page 712}

Whether or not ventilator-dependent patients without ALI/ARDS should be managed with lower $V_{T}$ remains unsettled, with some studies suggesting that lower $\mathrm{V}_{\mathrm{T}}$ with limitation of inspiratory pressures may impact patient outcomes such as mortality, ventilator-free days (VFDs), and post-intubation ALI/ARDS. . $^{15-21}$

We performed an a priori, pre-specified analysis of a 22-center, international cohort study of patients at risk of ALI/ARDS.22 Using this cohort, we examined contemporary ventilator practice in patients with and without ALI/ ARDS, seeking to determine: variables impacting administered $\mathrm{V}_{\mathrm{T}}$; whether or not lower $\mathrm{V}_{\mathrm{T}}$ is associated with post-intubation ALI/ARDS; and the impact of ALI/ARDS

\footnotetext{
Anesthesiology, University of Michigan, Ann Arbor, Michigan. Dr Park is affiliated with the Division of Acute Care Surgery, University of Michigan, Ann Arbor, Michigan. Dr Gong is affiliated with the Division of Critical Care Medicine, Montefiore Medical Center, Department of Medicine and Department of Epidemiology and Population Health, Albert Einstein College of Medicine, Bronx, New York. See the complete list of Lung Injury Prevention Study Investigators members below.

Dr Dabbagh has disclosed a relationship with Sanofi-Aventis. Dr Malhotra was partly supported by National Institutes of Health grants R01 HL085188-01A2, R01 HL090897, K24 HL 093218, P01 HL 095491, and AHA0840159N, and has disclosed relationships with Philips, Sepracor, Cephalon, Apnex, Apnicure, Pfizer, Merck, SGS, SHC, Ethicon, and Medtronic. Dr Anderson has disclosed relationships with Solvay Pharmaceuticals, Optimer Pharmaceuticals, Cook Medical, Life Connection of Ohio, Edwards Lifesciences, Pfizer, Hospira, Medco, and Merck. Dr Gong was partly supported by National Heart, Lung, and Blood Institute grants HL60710, HL086667, and HL084060. The other authors have disclosed no conflicts of interest.
}

Correspondence: Steven Y Chang MD PhD, Division of Pulmonary and Critical Care Medicine, University of Medicine and Dentistry of New Jersey, New Jersey Medical School, 150 Bergen Street, UH-I354, Newark NJ 07103. E-mail: changsy@umdnj.edu.

DOI: $10.4187 /$ respcare. 01755

\section{QUICK LOOK}

\section{Current knowledge}

A tidal volume $\left(\mathrm{V}_{\mathrm{T}}\right)$ of $\leq 8 \mathrm{~mL} / \mathrm{kg}$ is associated with improved outcomes in mechanically ventilated patients with ALI/ARDS. Clinician adoption of low- $\mathrm{V}_{\mathrm{T}}$ ventilation has been slow. The impact of higher $\mathrm{V}_{\mathrm{T}}$ early during mechanical ventilation on the development of ALI/ARDS remains controversial.

\section{What this paper contributes to our knowledge}

Patients with ALI/ARDS were more likely to receive $\mathrm{V}_{\mathrm{T}} \leq 8 \mathrm{~mL} / \mathrm{kg}$, compared to non-ALI/ARDS patients. In this population, the development of ALI/ARDS postintubation was not associated with the initial $\mathrm{V}_{\mathrm{T}}$ setting. Resource utilization for patients with post-intubation ALI/ARDS was greater, despite mortality that was similar to ALI/ARDS patients. Interventions are needed to improve clinician adherence to low- $\mathrm{V}_{\mathrm{T}}$ ventilation in ALI/ARDS.

(both present on intubation and developing after intubation) on outcomes. We also looked at whether or not clinicians are consistently using lower $\mathrm{V}_{\mathrm{T}}$ years after publication of the 2000 ARDS Network study showing its mortality benefit. ${ }^{2}$ We hypothesized that lower $V_{T}$ ventilation would be associated with less post-intubation ALI/ ARDS.

\section{Methods}

\section{Study Design}

This is a secondary analysis of the Lung Injury Prevention Study (LIPS), which was a 22 center, observational, cohort study conducted from March to August 2009, approved by local institutional review boards. ${ }^{22}$ Nineteen hospitals enrolled patients prospectively, while 3 hospitals collected retrospective data.

\section{Study Subjects}

Patients $\geq 18$ years old admitted to the hospital with $\geq 1$ risk factor for ALI/ARDS (sepsis, shock, pancreatitis, pneumonia, aspiration, high-risk trauma, and high-risk surgery) were enrolled from emergency departments or operating rooms. Subjects were excluded from the LIPS study if they had ALI/ARDS within 6 hours of assessment, were transferred from an outside institution, died in the emergency department, were admitted for palliation, or were re-admitted during the study period. For this analysis we 


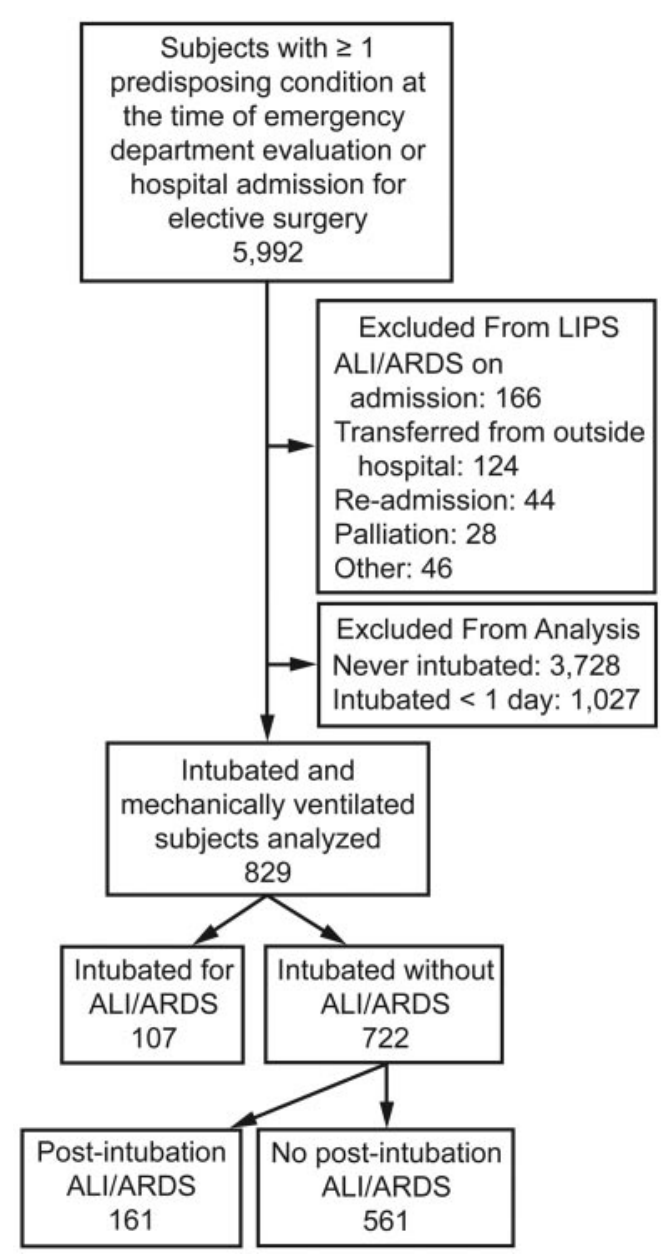

Fig. 1. Flow chart of screening and case assessment. LIPS = Lung Injury Prevention Study. ALI = acute lung injury.

excluded patients who were either never mechanically ventilated or who received mechanical ventilation for $\leq 1$ day.

\section{Data Collection}

As detailed elsewhere, baseline characteristics, including sociodemographic data, comorbidities, and clinical variables were collected in the first 6 hours of evaluation in the emergency department or hospital admission for high risk elective surgery. ${ }^{22}$ For this study the initial ventilator settings and parameters were recorded for subjects whether or not they were intubated because of ALI/ARDS. Set volumes and pressures were collected, regardless of ventilator strategies, when data were available. Additionally, for those who developed post-intubation ALI/ARDS, the first recorded ventilator settings after onset of ALI/ ARDS were noted.

De-identified subject information was entered into a secure, password-protected National Institutes of Health supported Web site (REDCap, http://www.project-redcap.org).

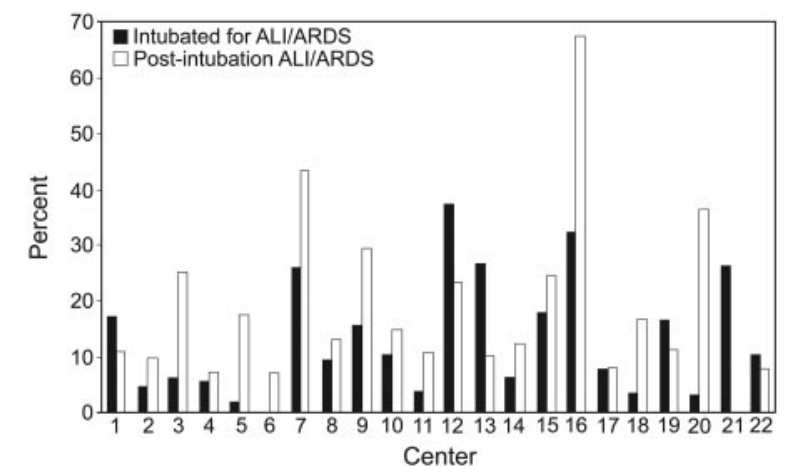

Fig. 2. Intercenter variation in rate of subjects intubated for acute lung injury (ALI)/ARDS $(n=107)$ and developing post-intubation ALI/ARDS $(n=161)$.

Site investigators were responsible for the quality of data collection according to standardized definitions. Investigators and study coordinators took an online tutorial regarding study definitions and ALI/ARDS assessment. Electronic range checks and validation rules were utilized to eliminate erroneous data entry and numerical artifacts.

\section{Outcomes Measures}

The primary outcome was the initial set $\mathrm{V}_{\mathrm{T}}$ and PEEP on intubation of subjects who never developed ALI/ARDS (never-ALI/ARDS), in subjects intubated because of ALI/ ARDS, and in subjects developing ALI/ARDS after intubation. ALI and the ARDS were defined as per AmericanEuropean Consensus Conference guidelines. ${ }^{23}$ Other outcomes included the development of ALI/ARDS among subjects without ALI/ARDS on initial intubation, and hospital outcomes such as mortality and VFDs for 28 days.

\section{Data Analysis}

Normality testing was performed using the Kolmogorov-Smirnov test. Continuous variables were compared using the Student $t$ test or the Mann-Whitney test, as per normality testing. Categorical variables were compared using the chi-square test or Fisher exact test. One-way analysis of variance was performed to look for intercenter variation in $\mathrm{V}_{\mathrm{T}}$ settings. When performed, paired analysis was performed using the Wilcoxon signed-rank test. We defined $<8 \mathrm{~mL} / \mathrm{kg}$ PBW as the upper limit for lower $\mathrm{V}_{\mathrm{T}}$ ventilation, since the ARDS Network low- $\mathrm{V}_{\mathrm{T}}$ trial allowed liberalization to $8 \mathrm{~mL} / \mathrm{kg}$ PBW for severe patient discomfort if plateau pressures remained $\leq 30 \mathrm{~cm} \mathrm{H}_{2} \mathrm{O}$. Because of uncertainty regarding PEEP, we did not pre-specify "lung-protective" levels. Multivariate analysis was performed using conditional logistic regression, stratified by center to account for center differences. Two models were built. One to examine clinical factors associated with 


\section{Contemporary Ventilator Management in Patients With and at Risk of ALi/ARDS}

Table 1. Baseline Characteristics of Study Subjects

\begin{tabular}{|c|c|c|c|c|c|}
\hline & $\begin{array}{c}\text { Total } \\
n=829\end{array}$ & $\begin{array}{c}\text { Never ALI/ARDS } \\
n=561\end{array}$ & $\begin{array}{l}\text { ALI/ARDS } \\
n=107\end{array}$ & $\begin{array}{l}\text { Post-intubation ALI/ARDS } \\
n=161\end{array}$ & $P$ \\
\hline Age, median (IQR) y, $n=829$ & $57.0(43.0-69.0)$ & $58.0(43.0-70.0)$ & $57.0(44.0-68.0)$ & $56.0(42.0-67.0)$ & .56 \\
\hline Male, no. $(\%), n=829$ & $520(62.7)$ & $339(60.4)$ & $63(58.9)$ & $118(73.3)$ & .008 \\
\hline Race, no. $(\%), n=813$ & & & & & .002 \\
\hline White & $516(63.5)$ & $353(64.2)$ & $73(69.5)$ & $90(57.0)$ & \\
\hline Black & $151(18.6)$ & $114(20.7)$ & $10(9.5)$ & $27(17.1)$ & \\
\hline Other & $146(18.6)$ & $83(15.1)$ & $22(21.0)$ & $41(25.9)$ & \\
\hline APACHE II score, median (IQR) & $13(9-20)$ & $13(8-19)$ & $13(8-17)$ & $16(11-22)$ & .001 \\
\hline LIPS score, median (IQR) & $5(4-7)$ & $5(3-6)$ & $5(4-7)$ & $6(5-8)$ & $<.001$ \\
\hline Height, median (IQR) cm, $n=741$ & $170.2(162.6-178.0)$ & $170.2(162.6-177.8)$ & $170.0(162.0-180.0)$ & $172.0(165.0-180.0)$ & .23 \\
\hline Predicted body weight, $\mathrm{kg}$ (IQR), $n=740$ & $66.0(55.2-73.3)$ & $66.0(55.1-73.1)$ & $61.9(54.2-75.1)$ & $67.4(58.7-75.1)$ & .14 \\
\hline Weight, median (IQR) kg, $n=781$ & $79.4(67.0-93.4)$ & $78.0(65.9-94.0)$ & $80.0(68.0-90.4)$ & $82.0(68.0-94.3)$ & .22 \\
\hline BMI, median (IQR) $\mathrm{kg} / \mathrm{m}^{2}, n=738$ & $26.9(23.3-31.3)$ & $26.8(23.2-31.2)$ & $26.6(23.9-30.9)$ & $27.6(23.7-31.8)$ & .83 \\
\hline \multicolumn{6}{|l|}{ Predisposing conditions, no. (\%) } \\
\hline Aspiration & $96(11.6)$ & $67(11.9)$ & $5(4.7)$ & $24(14.9)$ & .03 \\
\hline Pneumonia & $160(19.3)$ & $88(15.7)$ & $37(34.6)$ & $35(21.7)$ & $<.001$ \\
\hline Pancreatitis & $20(2.4)$ & $13(2.3)$ & $6(5.6)$ & $1(0.6)$ & .03 \\
\hline Sepsis & $202(24.4)$ & $113(20.1)$ & $43(40.2)$ & $46(28.6)$ & $<.001$ \\
\hline Shock & $136(16.4)$ & $77(13.7)$ & $18(16.8)$ & $41(25.5)$ & .002 \\
\hline Lung contusion & $57(6.9)$ & $34(6.1)$ & $6(5.6)$ & 17 (10.6) & .12 \\
\hline Smoke inhalation & $11(1.3)$ & $7(1.2)$ & $0(0.0)$ & $4(2.5)$ & .21 \\
\hline Near drowning & $1(0.1)$ & $0(0)$ & $0(0.0)$ & $1(0.6)$ & .13 \\
\hline Multiple fractures & $49(5.9)$ & $30(5.3)$ & $9(8.4)$ & $10(6.2)$ & .46 \\
\hline Traumatic brain injury & $128(15.4)$ & $89(15.9)$ & $8(7.5)$ & $31(19.3)$ & .03 \\
\hline Cardiac surgery & $136(16.4)$ & $109(19.4)$ & $10(9.3)$ & 17 (10.6) & .003 \\
\hline Aortic surgery & $37(4.5)$ & $21(3.7)$ & $3(2.8)$ & $13(8.1)$ & .043 \\
\hline Thoracic surgery & $26(3.1)$ & $19(3.4)$ & $5(4.7)$ & $2(1.2)$ & .24 \\
\hline Spine surgery & $40(4.8)$ & $27(4.8)$ & $4(3.7)$ & $9(5.6)$ & .79 \\
\hline Acute abdomen & $46(5.5)$ & $30(5.3)$ & $10(9.3)$ & $6(3.7)$ & .14 \\
\hline Blood product transfusion & $390(47.0)$ & $259(46.2)$ & $53(49.5)$ & $78(48.4)$ & .75 \\
\hline \multicolumn{6}{|l|}{$\begin{array}{l}\text { APACHE }=\text { Acute Physiology and Chronic Health Evaluation } \\
\text { LIPS }=\text { Lung Injury Prevention Study } \\
\text { BMI = body mass index }\end{array}$} \\
\hline
\end{tabular}

$\mathrm{V}_{\mathrm{T}} \geq 8 \mathrm{~mL} / \mathrm{kg}$ PBW, and the second to examine the effect of initial $\mathrm{V}_{\mathrm{T}} \geq 8 \mathrm{~mL} / \mathrm{kg}$ PBW on the subsequent development of post-intubation ALI/ARDS. Variables were included in the model if significantly associated with the outcome on univariate analysis. The LIPS score was not included in the model for predictors for $\mathrm{V}_{\mathrm{T}}$ of $\geq 8 \mathrm{~mL} / \mathrm{kg}$ PBW because this was not available to the clinicians during the study. Significance was defined as $P<.05$. We report $95 \%$ confidence intervals, and all tests used were 2 -sided. Data are expressed as median and IQR or percentage.

\section{Results}

Of 5,992 at-risk screened subjects, 5,584 were enrolled into the LIPS study (Fig. 1). Of the 5,584, 3,728 patients were never intubated, and 1,027 were intubated for $\leq 1$ day and were excluded from analysis. Of the remaining 829 ventilated patients, 107 (12.9\%) were intubated for ALI/ ARDS, while 722 did not fulfill the ALI/ARDS criteria at onset of mechanical ventilation (no-ALI/ARDS-onintubation) (see Fig. 1).

Of those 722 no-ALI/ARDS-on-intubation subjects, $161(22 \%)$ developed post-intubation ALI/ARDS, while 561 did not (see Fig. 1). The overall incidence of subjects intubated for ALI/ARDS varied between centers, from $0 \%$ to $37 \%$, while the incidence of post-intubation ALI/ ARDS varied from $0 \%$ to $68 \%(P<.001)$ (Fig. 2). Baseline characteristics of subjects are listed in Table 1, and there were differences in sex, race, and predisposing conditions (aspiration, pneumonia, pancreatitis, sepsis, shock, traumatic brain injury, cardiac surgery, and aortic surgery). Subjects who developed post-intubation ALI/ARDS had a higher severity of illness, as reflected by both Acute Physiology and Chronic Health Evaluation (APACHE II) and LIPS. 

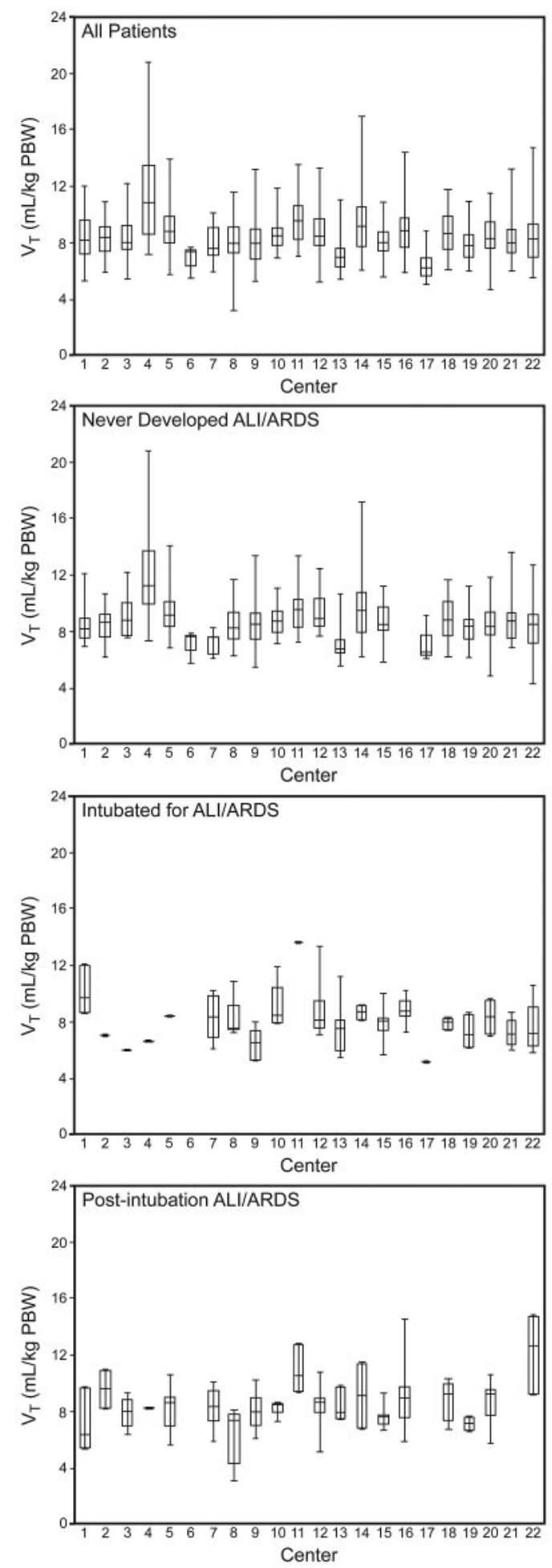

Fig. 3. Intercenter variation in initial tidal volume $\left(\mathrm{V}_{\mathrm{T}}\right)$ settings among all intubated and mechanically ventilated subjects $(n=829)$, subjects who never developed ALI/ARDS ( $n=561$ ), subjects intubated because of ALI/ARDS $(n=107)$, and subjects with postintubation ALI/ARDS $(n=161)$. The horizontal lines represent the medians, the tops and bottoms of the boxes represent quintiles 1 and 3 , and the whisker bars represent the upper and lower limits. For all the comparisons, $P$ via analysis of variance is $<.003$.
We compared initial ventilator settings and pressures between the 107 ALI/ARDS-on-intubation and the 722 no-ALI/ARDS-on-intubation subjects. There was considerable intercenter variability in the initial $\mathrm{V}_{\mathrm{T}}$ administered to all intubated subjects (from 6.16 [IQR 5.77-6.96] mL/kg PBW to 10.8 [IQR $8.64-13.5] \mathrm{mL} / \mathrm{kg}$ PBW), and in the various subsets of subjects, including those never developing ALI/ARDS (from 6.32 [IQR 6.16-7.59] mL/kg PBW to 11.13 [IQR $9.84-13.58$ ] $\mathrm{mL} / \mathrm{kg}$ PBW), those intubated because of ALI/ARDS (from 5.10 to $13.58 \mathrm{~mL} / \mathrm{kg}$ PBW), and those developing post-intubation ALI/ARDS (from 6.42 [IQR 5.40-9.66] mL/kg PBW to 12.64 (IQR 9.30$14.75 \mathrm{~mL} / \mathrm{kg}$ PBW) (Fig. 3). ALI/ARDS subjects had higher plateau pressure, lower compliance, and a greater likelihood of being managed with lower set $\mathrm{V}_{\mathrm{T}}$ (7.96 [IQR $7.14-8.94$ ] $\mathrm{mL} / \mathrm{kg} \mathrm{PBW}$ versus 8.45 [IQR 7.50-9.55] $\mathrm{mL} / \mathrm{kg}$ PBW, $P=.004)$ and higher set PEEP (6.5 [5-10] $\mathrm{cm}_{2} \mathrm{O}$ vs 5 [5-6] $\mathrm{cm} \mathrm{H}_{2} \mathrm{O}, P<.001$ ) (Table 2).

We examined factors influencing the delivery of lower $\mathrm{V}_{\mathrm{T}}(<8 \mathrm{~mL} / \mathrm{kg} \mathrm{PBW})$ to subjects without ALI/ARDS at onset of ventilation (Table 3 ). More severely ill subjects were given lower $\mathrm{V}_{\mathrm{T}}$, as reflected by higher APACHE II and LIPS, as were subjects intubated for conditions associated with higher risk of ALI/ARDS such as pneumonia or shock. Subjects on lower $V_{T}$ ventilation were more likely to be male, taller, and less obese, with lower body mass index. Multivariate analysis, after accounting for center variability, confirmed that shorter and heavier subjects received $\mathrm{V}_{\mathrm{T}} \geq 8 \mathrm{~mL} / \mathrm{kg}$ PBW, while subjects with pneumonia were less likely to receive $\mathrm{V}_{\mathrm{T}} \geq 8 \mathrm{~mL} / \mathrm{kg} \mathrm{PBW}$ (Table 4). Despite the tendency to administer lower $V_{T}$ to sicker subjects, there was no association between its use and outcomes such as mortality, VFDs, or stay in subjects intubated without ALI (Table 5).

In the 107 subjects intubated because of ALI/ARDS, ALI/ARDS occurred 2 (IQR 1-3) days after admission or high-risk surgery. For 161 post-intubation ALI/ARDS subjects, ALI/ARDS occurred 4 (IQR 2-7) days after admission or high-risk surgery, or 2 (IQR 1-4) days after intubation. Among those intubated without ALI/ARDS, initial $\mathrm{V}_{\mathrm{T}}$ and PEEP did not differ between the 161 who developed post-intubation ALI/ARDS and the 561 who did not (Table 6). When adjusted for non-ventilation risk factors, post-intubation ALI/ARDS subjects had higher peak pressure (27 [IQR 21-34] $\mathrm{cm} \mathrm{H} \mathrm{H}_{2} \mathrm{O}$ ) than never-ALI/ARDS subjects $(25$ [IQR $\left.20-31] \mathrm{cm} \mathrm{H}_{2} \mathrm{O}\right)(P=.01)$, but there was no difference in plateau pressure $(P=.11)$ or compliance $(P=.08)$. Multivariate analysis, after adjusting for sex, white race, pneumonia, sepsis, shock, cardiac surgery, aortic surgery, LIPS, and APACHE 2 score, did not reveal $\mathrm{V}_{\mathrm{T}} \geq 8 \mathrm{~mL} / \mathrm{kg}$ PBW to be associated with post-intubation ALI/ARDS (adjusted odds ratio 1.30, 95\% CI 0.74-2.29). Male sex (adjusted odds ratio 2.50, 95\% CI 1.31-4.78), LIPS (adjusted odds ratio 1.24/unit increase, 95\% CI 1.10- 


\section{Contemporary Ventilator Management in Patients With and at Risk of ALi/ARDS}

Table 2. Initial Ventilator Settings and Inspiratory Pressures

\begin{tabular}{|c|c|c|c|c|}
\hline & $\begin{array}{c}\text { Total } \\
n=829\end{array}$ & $\begin{array}{c}\text { No ALI/ARDS } \\
\text { on Intubation } \\
n=722\end{array}$ & $\begin{array}{c}\text { ALI/ARDS } \\
n=107\end{array}$ & $P$ \\
\hline Volume preset mode, no. (\%), $n=799$ & $656(82.1)$ & 449 (83.9) & $77(74.0)$ & .02 \\
\hline $\mathrm{V}_{\mathrm{T}}$, median (IQR) mL, $n=769$ & $550(500-600)$ & $550(500-600)$ & $500(450-600)$ & .002 \\
\hline $\mathrm{V}_{\mathrm{T}}$, median $(\mathrm{IQR}) \mathrm{mL} / \mathrm{kg} \mathrm{PBW}, n=691$ & $8.36(7.38-9.54)$ & $8.45(7.50-9.55)$ & $7.96(7.14-8.94)$ & .004 \\
\hline $\mathrm{V}_{\mathrm{T}}$, median $(\mathrm{IQR}) \mathrm{mL} / \mathrm{kg} \mathrm{ABW}, n=723$ & $6.82(5.84-8.00)$ & $6.82(5.88-8.00)$ & $6.63(5.42-7.75)$ & .06 \\
\hline $\mathrm{V}_{\mathrm{T}} \geq 8 \mathrm{~mL} / \mathrm{kg}$ PBW, no. $(\%)$ & $411(59.5)$ & $369(61.5)$ & $42(46.2)$ & .005 \\
\hline $\mathrm{V}_{\mathrm{T}} \geq 10 \mathrm{~mL} / \mathrm{kg}$ PBW, no. (\%) & $113(16.4)$ & $102(17.0)$ & $11(12.1)$ & .24 \\
\hline PEEP, median (IQR) $\mathrm{cm} \mathrm{H}_{2} \mathrm{O}, n=779$ & $5(5-6)$ & $5(5-5)$ & $6.5(5-10)$ & $<.001$ \\
\hline Peak pressure, median (IQR) $\mathrm{cm} \mathrm{H}_{2} \mathrm{O}, n=701$ & $25(20-32)$ & $25(20-31)$ & $26(22-33)$ & .18 \\
\hline Plateau pressure, median (IQR) $\mathrm{cm} \mathrm{H}_{2} \mathrm{O}, n=407$ & $19(16-24)$ & $19(16-24)$ & $22(18-29)$ & .001 \\
\hline Compliance, median (IQR) mL/cm $\mathrm{H}_{2} \mathrm{O}, n=385$ & $38.5(28.3-50.0)$ & $39.3(29.4-51.0)$ & $32.1(22.6-44.0)$ & .005 \\
\hline $\begin{array}{l}\text { ALI = acute lung injury } \\
\mathrm{V}_{\mathrm{T}}=\text { tidal volume } \\
\text { PBW = predicted body weight } \\
\text { ABW = actual body weight }\end{array}$ & & & & \\
\hline
\end{tabular}

1.39/unit increase), and cardiac surgery (adjusted odds ratio 0.21 , 95\% CI $0.07-0.55)$ were associated with postintubation ALI/ARDS. Sensitivity analyses comparing postintubation ALI/ARDS in subjects ventilated with $<6$ versus $\geq 8 \mathrm{~mL} / \mathrm{kg} \mathrm{PBW}$, or with $<6$ versus $\geq 10 \mathrm{~mL} / \mathrm{kg} \mathrm{PBW}$, did not reveal association between the use of high $\mathrm{V}_{\mathrm{T}}$ ventilation and post-intubation ALI/ARDS $(P>.30)$, but the analysis was limited by the loss of power from the exclusion of patients with $\mathrm{V}_{\mathrm{T}}$ outside of the comparison groups.

We examined changes in set $\mathrm{V}_{\mathrm{T}}$ and PEEP among 161 post-intubation ALI/ARDS subjects, before and after development of ALI/ARDS (Table 7). After development of post-intubation ALI/ARDS, set volumes decreased from 8.40 (IQR 7.38-9.37) $\mathrm{mL} / \mathrm{kg} \mathrm{PBW}$ to 7.97 (IQR 6.909.23) $\mathrm{mL} / \mathrm{kg}$ PBW $(P<.001)$, while set PEEP increased from 5 (IQR 5-6) $\mathrm{cm} \mathrm{H}_{2} \mathrm{O}$ to 8 (IQR 5-10) $\mathrm{cm} \mathrm{H}_{2} \mathrm{O}$ $(P<.001)$ (see Table 7).

Hospital outcomes in the ALI/ARDS-on-intubation and post-intubation ALI/ARDS subjects were examined. Mortality increased for subjects with either ALI/ARDS or postintubation ALI/ARDS: $16.6 \%$ in never-ALI/ARDS versus $24.3 \%$ in ALI/ARDS group and $25.5 \%$ in post-intubation ALI/ARDS $(P=.02)$. VFDs and stay were influenced by the presence or absence of ALI/ARDS, whether or not subjects were intubated for ALI/ARDS or developed post-intubation ALI/ARDS (Table 8). Although subjects with ALI/ ARDS and post-intubation ALI/ARDS had similar mortality, the post-intubation ALI/ARDS subjects had significantly fewer VFDs (18 [IQR 12-24] days versus 22 [IQR 15-25] days, $P=.005)$ and longer ICU and hospital stay.

\section{Discussion}

In this large, contemporary survey of mechanical ventilation practice, we observed substantial variability in ven- tilator settings that was not entirely explained by subjects' risk for ALI/ARDS. Post-intubation ALI/ARDS subjects constituted more than half of all ALI/ARDS in this study, with equally poor survival as subjects intubated because of ALI/ARDS, but longer ICU stay and fewer VFDs. Ventilator settings and administration of $\mathrm{V}_{\mathrm{T}}<8 \mathrm{~mL} / \mathrm{kg} \mathrm{PBW}$ were not associated with development of post-intubation ALI/ARDS or outcomes.

Lung-protective strategies have been shown to decrease mortality and ventilator utilization in subjects with established ALI/ARDS. ${ }^{1-4}$ Despite this evidence, low $\mathrm{V}_{\mathrm{T}}$ has not been consistently applied. ${ }^{5-7,10}$ In our study we found that among subjects intubated for ALI/ARDS, the median $\mathrm{V}_{\mathrm{T}}$ was $7.96(\mathrm{IQR} 7.14-8.94) \mathrm{mL} / \mathrm{kg}$ PBW. While this is lower than the median of $\sim 10 \mathrm{~mL} / \mathrm{kg}$ PBW from reports in 2000 and 2001, it is higher than the median of 6.8 (IQR 6.1-7.7) $\mathrm{mL} / \mathrm{kg}$ PBW used by ARDS Network sites in 2005.5,6,24 Additionally, a substantial number of subjects who were intubated because of ALI/ARDS received initial $\mathrm{V}_{\mathrm{T}}>8 \mathrm{~mL} / \mathrm{kg} \mathrm{PBW}$ or even $>10 \mathrm{~mL} / \mathrm{kg} \mathrm{PBW}$ (see Table 2). There does, however, seem to be a trend, over time, toward decreasing $\mathrm{V}_{\mathrm{T}}$, and we believe that our more recent multicenter study of both academic and community non-ARDS-Network hospitals may better reflect contemporary ventilator practices, as other reports have found that it may take 5-10 years after seminal studies to influence practice. $^{25}$

Notably, clinicians in our study seemed to respond to both ALI/ARDS and post-intubation ALI/ARDS by lowering $V_{T}$ and increasing PEEP. Median $V_{T}$ for all invasively ventilated subjects in our study was lower than in a recent European study of intubated and ventilated patients (6.8 versus $8.0 \mathrm{~mL} / \mathrm{kg}$ actual body weight). ${ }^{11}$ Importantly, this occurred without pre-specified ventilator management 


\section{Contemporary Ventilator Management in Patients With and at Risk of ALi/ARDS}

Table 3. Comparison of Subjects Without ALI/ARDS at Onset of Mechanical Ventilation, Initially Treated With Tidal Volume of $<8 \mathrm{~mL} / \mathrm{kg}$ $\mathrm{PBW}$ versus $\geq 8 \mathrm{~mL} / \mathrm{kg}$ PBW*

\begin{tabular}{|c|c|c|c|c|}
\hline & $\begin{array}{c}\text { Total } \\
n=600\end{array}$ & $\begin{array}{c}\mathrm{V}_{\mathrm{T}}<8 \mathrm{~mL} / \mathrm{kg} \mathrm{PBW} \\
n=231\end{array}$ & $\begin{array}{c}\mathrm{V}_{\mathrm{T}} \geq 8 \mathrm{~mL} / \mathrm{kg} \mathrm{PBW} \\
n=369\end{array}$ & $P$ \\
\hline Age, median (IQR) y & $58(43-70)$ & $56(39-69)$ & $58(45-70)$ & .17 \\
\hline Male, no. $(\%)$ & $380(63.3)$ & $189(81.8)$ & $191(51.8)$ & $<.001$ \\
\hline \multicolumn{5}{|l|}{ Race, no. $(\%), n=594$} \\
\hline White & $368(62.0)$ & $148(65.2)$ & $220(59.9)$ & .20 \\
\hline Black & $122(20.5)$ & $38(16.7)$ & $84(22.9)$ & \\
\hline Other & $104(17.5)$ & $41(18.1)$ & $63(17.2)$ & \\
\hline APACHE II, median (IQR) & $14(9-21)$ & $15(9-22)$ & $13(8-20)$ & .03 \\
\hline LIPS score, median (IQR) & $5(4-7)$ & $6(4-8)$ & $5(4-7)$ & $<.001$ \\
\hline Height, median (IQR) cm, $n=741$ & $170.2(162.6-178.0)$ & $178.0(170.2-182.9)$ & $167.6(160.0-173.0)$ & $<.001$ \\
\hline PBW, median (IQR) kg, $n=740$ & $66.1(56.5-73.3)$ & $73.1(66.0-77.8)$ & $61.5(53.3-68.8)$ & $<.001$ \\
\hline Weight, median (IQR) $\mathrm{kg}, n=781$ & $80.0(67.0-93.8)$ & $80.0(69.0-95.0)$ & $78.5(66.0-93.3)$ & .33 \\
\hline BMI, median (IQR), $n=738$ & $26.9(23.3-31.2)$ & $25.4(22.4-29.3)$ & $28.1(23.8-32.6)$ & $<.001$ \\
\hline \multicolumn{5}{|l|}{ Predisposing conditions, no. (\%) } \\
\hline Aspiration & $79(13.2)$ & $37(16.0)$ & $42(11.4)$ & .10 \\
\hline Pneumonia & $97(16.2)$ & $55(23.8)$ & $42(11.4)$ & $<.001$ \\
\hline Pancreatitis & $10(1.7)$ & $4(1.7)$ & $6(1.6)$ & .92 \\
\hline Sepsis & $134(22.3)$ & $60(26.0)$ & $74(20.1)$ & .09 \\
\hline Shock & $105(17.5)$ & $55(23.8)$ & $50(13.6)$ & .001 \\
\hline Lung contusion & $47(7.8)$ & $20(8.7)$ & $27(7.3)$ & .55 \\
\hline Smoke inhalation & $8(1.3)$ & $2(0.9)$ & $6(1.6)$ & .43 \\
\hline Near drowning & $1(0.2)$ & $1(0.4)$ & $0(0)$ & .21 \\
\hline Multiple fractures & $33(5.5)$ & $16(6.9)$ & $17(4.6)$ & .23 \\
\hline Traumatic brain injury & $103(17.2)$ & $40(17.3)$ & $63(17.1)$ & .94 \\
\hline Cardiac surgery & $106(17.7)$ & $27(11.7)$ & $79(21.4)$ & .002 \\
\hline Aortic surgery & $31(5.2)$ & $11(4.8)$ & $20(5.4)$ & .72 \\
\hline Thoracic surgery & $15(2.5)$ & $4(1.7)$ & $11(3.0)$ & .34 \\
\hline Spine surgery & $32(5.3)$ & $8(3.5)$ & $24(6.5)$ & .11 \\
\hline Acute abdomen & $27(4.5)$ & $8(3.5)$ & $19(5.1)$ & .33 \\
\hline Blood product transfusion & $295(49.2)$ & $108(46.8)$ & $187(50.7)$ & .35 \\
\hline $\begin{array}{l}\text { * Analysis limited to the } 600 / 722(83 \%) \text { subjects } \\
\text { ALI = acute lung injury } \\
\text { APACHE = Acute Physiology and Chronic Hea } \\
\text { LIPS = Lung Injury Prevention Study } \\
\text { PBW = predicted body weight } \\
\text { BMI = body mass index }\end{array}$ & ble tidal volume $\left(\mathrm{V}_{\mathrm{T}}\right)$ and ide & ght (IBW) data. & & \\
\hline
\end{tabular}

strategies. Clinicians at each center managed ventilators according to their own standards or guidelines. In addition to subjects with ALI/ARDS, subjects with a high risk of ALI/ARDS (higher LIPS) and those with milder degrees of lung injury (pneumonia) seemed more likely to receive lower $\mathrm{V}_{\mathrm{T}}$, although this did not impact development of post-intubation ALI/ARDS.

Patient acuity was not the only determinant of ventilator settings. We observed substantial inter-center variability (see Fig. 3). This may be due to differences in ICU staffing and provider preference, as suggested by the finding that cardiac surgery subjects were less likely to receive lower $\mathrm{V}_{\mathrm{T}}$ ventilation. However, we also found that shorter and heavier subjects were less likely to receive $\mathrm{V}_{\mathrm{T}}<8 \mathrm{~mL} / \mathrm{kg}$ PBW, suggesting that providers often ignore height when determining initial ventilator settings, ${ }^{26}$ although height, along with sex, is the primary determinant of predicted body weight, and thus $\mathrm{V}_{\mathrm{T}}$. Providers may rely on actual body weight, predisposing heavier subjects to higher $\mathrm{V}_{\mathrm{T}}$. Studies on obesity and ALI/ARDS have suggested similar practice patterns in other cohorts. ${ }^{27,28}$ Alternatively, initial ventilator settings at many centers may be set at a predetermined default volume, and as we captured set $\mathrm{V}_{\mathrm{T}}$ immediately after intubation and after development of postintubation ALI/ARDS, we may have recorded volumes not yet modified by clinicians.

Although our hypothesis that less post-intubation ALI/ ARDS would occur with lower $\mathrm{V}_{\mathrm{T}}$ ventilation $(<8 \mathrm{~mL} / \mathrm{kg}$ PBW) was consistent with the findings of a 2010 prospective, randomized study, ${ }^{15}$ we did not detect an influence of $\mathrm{V}_{\mathrm{T}}$. Three historical cohort studies identified high airway pressures and $\mathrm{V}_{\mathrm{T}}$ as risk factors for post-intubation 


\section{Contemporary Ventilator Management in Patients With and at Risk of ALi/ARDS}

Table 4. Factors Associated With Greater Odds of Receiving $\geq 8 \mathrm{~mL} / \mathrm{kg}$ PBW on Initial Ventilation in the Subjects Without ALI/ARDS at Onset of Mechanical Ventilation, After Adjusting for Center*

\begin{tabular}{lccc}
\hline \hline & $\begin{array}{l}\text { Odds } \\
\text { Ratio }\end{array}$ & $95 \%$ CI & $P$ \\
\hline Sex & 0.75 & $0.45-1.25$ & .26 \\
Height & 0.89 & $0.88-0.89$ & $<.001$ \\
BMI & 1.08 & $1.04-1.12$ & $<.001$ \\
Sepsis & 0.79 & $0.44-1.41$ & .42 \\
Pneumonia & 0.30 & $0.16-0.57$ & $<.001$ \\
Shock & 0.81 & $0.44-1.48$ & .49 \\
APACHE II & 0.99 & $0.97-1.02$ & .64 \\
Cardiac Surgery & 1.43 & $0.71-2.88$ & .32 \\
& & &
\end{tabular}

$* \mathrm{R}^{2}=0.43$.

$\mathrm{PBW}=$ predicted body weight

$\mathrm{ALI}=$ acute lung injury

BMI $=$ body mass index

APACHE $=$ Acute Physiology and Chronic Health Evaluation
ALI/ARDS in patients requiring mechanical ventilation. ${ }^{16-18}$ In these studies, however, $\mathrm{V}_{\mathrm{T}}(>10 \mathrm{~mL} / \mathrm{kg} \mathrm{PBW})$ and airway pressure $\left(>30 \mathrm{~cm} \mathrm{H}_{2} \mathrm{O}\right)$ were higher than in our study, and likely more injurious. The difference between $\mathrm{V}_{\mathrm{T}}$ and PEEP, in our study, between those receiving what we defined as lower $\mathrm{V}_{\mathrm{T}}$ ventilation and those who did not, may not have been large enough to influence outcomes.

The lack of effect of $\mathrm{V}_{\mathrm{T}}$ on outcomes may have occurred due to timely clinician recognition of post-intubation ALI/ ARDS (see Table 7). That is, physicians responded by decreasing $\mathrm{V}_{\mathrm{T}}$ and increasing PEEP when subjects developed ALI/ARDS, thus minimizing differences in outcomes. Alternatively, it may be that $8 \mathrm{~mL} / \mathrm{kg} \mathrm{PBW}$ is sufficiently low to decrease adverse outcomes. Finally, the study may lack power to detect differences in outcomes with regards to ventilator management strategies, as it was not designed with this specific intent. Our study was limited by its observational nature, with inherent indica-

Table 5. Clinical Outcomes of Subjects Without ALI/ARDS at Onset of Ventilation (Based on Initial Tidal Volume)

\begin{tabular}{|c|c|c|c|c|}
\hline & $\begin{array}{c}\text { Total } \\
n=600\end{array}$ & $\begin{array}{c}\mathrm{V}_{\mathrm{T}}<8 \mathrm{~mL} / \mathrm{kg} \text { PBW } \\
n=231\end{array}$ & $\begin{array}{c}\mathrm{V}_{\mathrm{T}} \geq 8 \mathrm{~mL} / \mathrm{kg} \mathrm{PBW} \\
n=369\end{array}$ & $P$ \\
\hline Mortality, no. (\%), $n=600$ & $104(17.3)$ & $46(19.9)$ & $58(15.7)$ & .19 \\
\hline Ventilator-free days, median (IQR) d, $n=600$ & $24(17-26)$ & $24(17-26)$ & $24(17-26)$ & .45 \\
\hline ICU stay, median (IQR) d, $n=529$ & $7(4-15)$ & $7(4-15)$ & $7(4-15)$ & .88 \\
\hline Hospital stay, median (IQR) d, $n=600$ & $14(9-25)$ & $14(8-26)$ & $15(9-25)$ & .48 \\
\hline $\begin{array}{l}\text { ALI = acute lung injury } \\
V_{\mathrm{T}}=\text { tidal volume } \\
\text { PBW = predicted body weight }\end{array}$ & & & & \\
\hline
\end{tabular}

Table 6. Initial Ventilator Settings and Pressures Among the 722 Subjects Without ALI/ARDS at Onset of Mechanical Ventilation

\begin{tabular}{|c|c|c|c|c|}
\hline Variable & $\begin{array}{c}\text { Total } \\
n=722\end{array}$ & $\begin{array}{c}\text { Never } \\
\text { ALI/ARDS } \\
n=561\end{array}$ & $\begin{array}{c}\text { Post-intubation } \\
\text { ALI/ARDS } \\
n=161\end{array}$ & $P$ \\
\hline Volume preset mode, no. $(\%), n=695$ & $579(83.3)$ & $449(83.9)$ & $130(81.2)$ & .43 \\
\hline $\mathrm{V}_{\mathrm{T}}$, median (IQR) mL, $n=665$ & $550(500-600)$ & $550(500-600)$ & $550(500-600)$ & .27 \\
\hline $\mathrm{V}_{\mathrm{T}}$, median (IQR) mL/kg PBW, $n=600$ & $8.36(7.38-9.54)$ & $8.46(7.52-9.65)$ & $8.40(7.37-9.39)$ & .23 \\
\hline $\mathrm{V}_{\mathrm{T}}$, median (IQR) $\mathrm{mL} / \mathrm{kg} \mathrm{ABW}, n=600$ & $6.82(5.84-8.00)$ & $6.87(5.88-8.06)$ & $6.67(5.90-7.78)$ & .25 \\
\hline $\mathrm{V}_{\mathrm{T}} \geq 8 \mathrm{~mL} / \mathrm{kg}$ PBW, no. $(\%)$ & $369(61.5)$ & $282(62.4)$ & $87(58.8)$ & .43 \\
\hline $\mathrm{V}_{\mathrm{T}} \geq 10 \mathrm{~mL} / \mathrm{kg}$ PBW, no. (\%) & $102(17.0)$ & $84(18.6)$ & $18(12.2)$ & .07 \\
\hline PEEP, median (IQR) $\mathrm{cm} \mathrm{H}_{2} \mathrm{O}, n=673$ & $5(5-6)$ & $5(5-5)$ & $5(5-6)$ & .33 \\
\hline Peak pressure, median (IQR) $\mathrm{cm} \mathrm{H}_{2} \mathrm{O}, n=605$ & $25(20-32)$ & $25(20-31)$ & $27(21-34)$ & .01 \\
\hline Plateau pressure, median (IQR) $\mathrm{cm} \mathrm{H}_{2} \mathrm{O}, n=351$ & $19(16-24)$ & $19(15-23)$ & $19(17-25)$ & .11 \\
\hline Compliance, median (IQR) mL/cm $\mathrm{H}_{2} \mathrm{O}, n=329$ & $38.5(28.3-50.0)$ & $40.0(29.4-54.6)$ & $37.4(29.1-46.2)$ & .08 \\
\hline $\begin{array}{l}\text { ALI = acute lung injury } \\
V_{T}=\text { tidal volume } \\
\text { PBW = predicted body weight } \\
\text { ABW = actual body weight }\end{array}$ & & & & \\
\hline
\end{tabular}




\section{Contemporary Ventilator Management in Patients With and at Risk of ALi/ARDS}

Table 7. Ventilator Settings and Parameters Before and After Development of ALI/ARDS in the 161 Subjects Who Developed ALI/ARDS After Onset of Mechanical Ventilation

\begin{tabular}{|c|c|c|c|}
\hline & Before & After & $P^{*}$ \\
\hline $\mathrm{V}_{\mathrm{T}}, \mathrm{mL} / \mathrm{kg} \mathrm{PBW}$ & $8.40(7.38-9.37)$ & $7.97(6.90-9.23)$ & $<.001$ \\
\hline $\mathrm{V}_{\mathrm{T}}, \mathrm{mL} / \mathrm{kg} \mathrm{ABW}$ & $6.67(5.92-7.78)$ & $6.44(5.46-7.78)$ & $<.001$ \\
\hline $\mathrm{V}_{\mathrm{T}}, \mathrm{mL}$ & $550(500-600)$ & $510(450-600)$ & $<.001$ \\
\hline PEEP, $\mathrm{cm} \mathrm{H}_{2} \mathrm{O}$ & $5(5-6)$ & $8(5-10)$ & $<.001$ \\
\hline Plateau pressure, $\mathrm{cm} \mathrm{H}_{2} \mathrm{O}$ & $19(17-25)$ & $20(18-25)$ & .053 \\
\hline $\begin{array}{l}\text { Values are median (IQR). } \\
\text { * Paired analysis was performed usi } \\
\text { ALI = acute lung injury } \\
\mathrm{V}_{\mathrm{T}}=\text { tidal volume } \\
\text { PBW = predicted body weight } \\
\mathrm{ABW}=\text { actual body weight }\end{array}$ & & & \\
\hline
\end{tabular}

Table 8. Hospital Outcomes

\begin{tabular}{|c|c|c|c|c|c|}
\hline & $\begin{array}{c}\text { Total } \\
n=829\end{array}$ & $\begin{array}{c}\text { Never ALI/ARDS } \\
n=561\end{array}$ & $\begin{array}{c}\text { ALI/ARDS } \\
n=107\end{array}$ & $\begin{array}{c}\text { Post-intubation } \\
\text { ALI/ARDS } \\
n=161\end{array}$ & $P^{*}$ \\
\hline Mortality, no. (\%), $n=829$ & $160(19.3)$ & $93(16.6)$ & $26(24.3)$ & $41(25.5)$ & .02 \\
\hline Ventilator-free days, median (IQR), $n=829$ & $24(18-26)$ & $24(21-26)$ & $22(15-25)$ & $18(12-24)$ & $<.001$ \\
\hline ICU stay, median (IQR) d, $n=751$ & $7(4-15)$ & $6(3-12)$ & $9(5-17)$ & $12(6-19)$ & $<.001$ \\
\hline Hospital stay, median (IQR) d, $n=829$ & $14(9-24)$ & $13(8-23)$ & $15(10-24)$ & $19(10-29)$ & .001 \\
\hline
\end{tabular}

tion bias that this epidemiologic study could not assess. The ventilator settings were captured at single points in time, and the number of subjects with available plateau pressure was small. These shortcomings were balanced by its large size, and by its real-world, non-interventional design.

Little is known about the differences between ALI/ARDS and post-intubation ALI/ARDS. Our study showed that post-intubation ALI/ARDS constitutes the majority of cases of ALI/ARDS and that its incidence varies across centers. Although mortality in subjects with post-intubation ALI/ ARDS is similar to that in ALI/ARDS subjects, post-intubation ALI/ARDS subjects had longer stay and fewer VFDs. Why subjects with post-intubation ALI/ARDS have increased resource utilization is not entirely clear, but it is likely that the additional time spent on mechanical ventilation before development of ALI/ARDS may be additive, thus decreasing VFDs and increasing stay. It remains important to better understand factors influencing post-intubation ALI/ARDS, and how they may be manipulated to reduce its incidence. Indeed, a recent population-based study of hospital-acquired ALI/ARDS suggested that the incidence may be reduced with uniform adoption of quality-improvement initiatives aimed at reducing transfusion and $\mathrm{V}_{\mathrm{T}}$, and improving sepsis management. ${ }^{29}$

\section{Conclusions}

This multicenter, observational study suggests improved, but not ideal, adherence to lower $\mathrm{V}_{\mathrm{T}}$ ventilation in subjects with and at risk of ALI/ARDS. Although we observed variation in ventilator management related to factors other than patient condition, these were not associated with adverse outcomes. While subjects with ALI/ARDS and post-intubation ALI/ARDS had similar mortality, resource utilization for those with post-intubation ALI/ARDS was increased. Interventions improving adherence to low $\mathrm{V}_{\mathrm{T}}$ ventilation in ALI and ARDS are needed. Larger, robust, prospective studies examining the role of ventilator settings on the post-intubation ALI/ARDS should be performed.

United States Critical Illness and Injury Trials Group: Lung Injury Prevention Study Investigators

Beth Israel Deaconess Medical Center, Boston, Massachusetts: Daniel S Talmor MD, S Patrick Bender MD, Mauricio Garcia MD.

Brigham and Women's Hospital, Boston, Massachusetts: Peter C Hou MD, Jonathan M Barry, Iam Shempp, Atul Malhotra MD, Gyorgy Frendl MD PhD, Departments of Surgery, Internal Medicine, and Anesthesiology, Perioperative, and Pain Medicine.

Mayo Clinic, Rochester, Minnesota: Adil Ahmed MD, Ognjen Gajic MD, Michael Malinchoc MSc, Daryl J Kor MD, Bekele Afessa MD, Rodrigo Cartin-Ceba MD, Departments of Internal Medicine, Health Sciences Research, and Anesthesiology. 


\section{Contemporary Ventilator Management in Patients With and at Risk of ALi/ARDS}

Mount Sinai School of Medicine, New York, New York: Michelle Ng Gong MD MSc, Division of Pulmonary, Critical Care, and Sleep Medicine.

Temple University School of Medicine, Philadelphia, Pennsylvania: Nina T Gentile MD, Karen Stevenson MD, Brent Freeman, Sujatha Srinivasan MD, Department of Emergency Medicine.

Johns Hopkins University, Baltimore, Maryland: Jonathan Sevransky MD MHS, Medical Intensive Care Unit.

University of Medicine and Dentistry of New Jersey, Newark, New Jersey: Steven Y Chang PhD MD, Department of Pulmonary and Critical Care Medicine; Amee Patrawalla MD MPH, Carmelle Elie MD, Irram Hamdani MD, and Jason Seiden MD. University of Colorado, Denver, Colorado: Ivor Douglas MD, Pulmonary Sciences and Critical Care Medicine, School of Medicine.

University of Pennsylvania, Philadelphia, Pennsylvania: Mark Mikkelsen MD MSCE, Division of Pulmonary, Allergy, and Critical Care; Jason D Christie MD, David F Gaieski MD, Paul Lanken MD, Nuala Meyer MD, Chirag Sha MD.

University of Michigan, Ann Arbor, Michigan: Pauline K Park MD, Julie Harris, Department of Surgery; Lena Napolitano MD, Krishnan Raghavendran MBBS, Robert C Hyzy MD, James Blum MD.

University of Washington, Seattle, Washington: Timothy R Watkins MD, Division of Pulmonary and Critical Care Medicine, Harborview Medical Center; Steven Deem MD, Miriam Treggiari MD MPH.

University of Texas Southwestern Medical Center, Dallas, Texas: Adebola Adesanya MD MPH.

University of Illinois at Chicago: Ruxana Sadikot MD MRCP.

Wake Forest University Health Sciences, Winston-Salem, North Carolina: J Jason Hoth MD, Department of Surgery; Barbara Yoza $\mathrm{PhD}$

Mayo Clinic Jacksonville, Jacksonville, Florida: Emir Festic MD, Department of Critical Care Services.

Bridgeport Hospital, Yale New Haven Health, New Haven, Connecticut: David Kaufman MD, Pulmonary, Critical Care and Sleep Medicine, and Department of Respiratory Therapy.

Massachusetts General Hospital, Harvard Medical School, Boston, Massachusetts: Ednan Bajwa MD MPH, Atul Malhotra MD, B Taylor Thompson, David C Christiani MD MPH.

Akdeniz University, Antalyia, Turkey: Melike Cengiz MD PhD, Murat Yilmaz MD.

Miami Valley Hospital, Wright State University Boonshoft School of Medicine, Dayton, Ohio: Harry Anderson III MD; Kathryn Tchorz MD, Mary C McCarthy MD; David Uddin PhD DABCC CIP.

Uludag University, Bursa, Turkey: Remzi Iscimen MD.

University of Missouri, Columbia, Missouri: Ousama Dabbagh MD MSc, Department of Public Health; Nena Kallenbach.

Emory University, Atlanta, Georgia: Anette Esper MD, Greg Martin MD.

\section{REFERENCES}

1. Amato MB, Barbas CS, Medeiros DM, Magaldi RB, Schettino GP, Lorenzi-Filho G, et al. Effect of a protective-ventilation strategy on mortality in the acute respiratory distress syndrome. N Engl J Med 1998;338(6):347-354

2. The Acute Respiratory Distress Syndrome Network. Ventilation with lower tidal volumes as compared with traditional tidal volumes for acute lung injury and the acute respiratory distress syndrome. N Engl J Med 2000;342(18):1301-1308.

3. Villar J, Kacmarek RM, Perez-Mendez L, Aguirre-Jaime A. A high positive end-expiratory pressure, low tidal volume ventilatory strategy improves outcome in persistent acute respiratory distress syndrome: a randomized, controlled trial. Crit Care Med 2006;34(5): 1311-1318.

4. Putensen C, Theuerkauf N, Zinserling J, Wrigge H, Pelosi P. Metaanalysis: ventilation strategies and outcomes of the acute respiratory distress syndrome and acute lung injury. Ann Intern Med 2009; 151(8):566-576.

5. Weinert CR, Gross CR, Marinelli WA. Impact of randomized trial results on acute lung injury ventilator therapy in teaching hospitals. Am J Respir Crit Care Med 2003;167(10):1304-1309.

6. Young MP, Manning HL, Wilson DL, Mette SA, Riker RR, Leiter JC, et al. Ventilation of patients with acute lung injury and acute respiratory distress syndrome: has new evidence changed clinical practice? Crit Care Med 2004;32(6):1260-1265.

7. Ferguson ND, Frutos-Vivar F, Esteban A, Anzueto A, Alía I, Brower RG, et al. Airway pressures, tidal volumes, and mortality in patients with acute respiratory distress syndrome. Crit Care Med 2005;33(1): 21-30.

8. Esteban A, Ferguson ND, Meade MO, Frutos-Vivar F, Apezteguía $\mathrm{C}$, Brochard L, et al. Evolution of mechanical ventilation in response to clinical research. Am J Respir Crit Care Med 2008;177(2):170-177.

9. Acute lung injury and the acute respiratory distress syndrome in Ireland: a prospective audit of epidemiology and management. Crit Care 2008;12(1):R30.

10. Linko R, Okkonen M, Pettila V, Perttila J, Parviainen I, Ruokonen E, et al. Acute respiratory failure in intensive care units. FINNALI: a prospective cohort study. Intensive Care Med 2009;35(8):1352-1361.

11. Metnitz PG, Metnitz B, Moreno RP, Bauer P, Del Sorbo L, Hoermann C, et al. Epidemiology of mechanical ventilation: analysis of the SAPS 3 database. Intensive Care Med 2009;35(5):816-825.

12. Brower RG, Lanken PN, MacIntyre N, Matthay MA, Morris A, Ancukiewicz M, et al. Higher versus lower positive end-expiratory pressures in patients with the acute respiratory distress syndrome. N Engl J Med 2004;351(4):327-336.

13. Meade MO, Cook DJ, Guyatt GH, Slutsky AS, Arabi YM, Cooper DJ, et al. Ventilation strategy using low tidal volumes, recruitment maneuvers, and high positive end-expiratory pressure for acute lung injury and acute respiratory distress syndrome: a randomized controlled trial. JAMA 2008;299(6):637-645.

14. Mercat A, Richard JC, Vielle B, Jaber S, Osman D, Diehl JL, et al. Positive end-expiratory pressure setting in adults with acute lung injury and acute respiratory distress syndrome: a randomized controlled trial. JAMA 2008;299(6):646-655.

15. Determann RM, Royakkers A, Wolthuis EK, Vlaar AP, Choi G, Paulus F, et al. Ventilation with lower tidal volumes as compared with conventional tidal volumes for patients without acute lung injury: a preventive randomized controlled trial. Crit Care 2010;14(1): R1.

16. Gajic O, Dara SI, Mendez JL, Adesanya AO, Festic E, Caples SM, et al. Ventilator-associated lung injury in patients without acute lung injury at the onset of mechanical ventilation. Crit Care Med 2004; 32(9):1817-1824.

17. Gajic O, Frutos-Vivar F, Esteban A, Hubmayr RD, Anzueto A. Ventilator settings as a risk factor for acute respiratory distress syndrome in mechanically ventilated patients. Intensive Care Med 2005; 31(7):922-926.

18. Jia X, Malhotra A, Saeed M, Mark RG, Talmor D. Risk factors for ARDS in patients receiving mechanical ventilation for $>48 \mathrm{~h}$. Chest 2008;133(4):853-861. 


\section{Contemporary Ventilator Management in Patients With and at Risk of ALi/ARDS}

19. Mascia L, Zavala E, Bosma K, Pasero D, Decaroli D, Andrews P, et al. High tidal volume is associated with the development of acute lung injury after severe brain injury: an international observational study. Crit Care Med 2007;35(8):1815-1820.

20. Plurad D, Martin M, Green D, Salim A, Inaba K, Belzberg H, et al. The decreasing incidence of late posttraumatic acute respiratory distress syndrome: the potential role of lung protective ventilation and conservative transfusion practice. J Trauma 2007;63(1):1-8.

21. Yilmaz M, Keegan MT, Iscimen R, Afessa B, Buck CF, Hubmayr $\mathrm{RD}$, et al. Toward the prevention of acute lung injury: protocolguided limitation of large tidal volume ventilation and inappropriate transfusion. Crit Care Med 2007;35(7):1660-1666.

22. Gajic O, Dabbagh O, Park PK, Adesanya A, Chang SY, Hou P, et al; US Critical Illness and Injury Trials Group: Lung Injury Prevention Study investigators. Early identification of patients at risk of acute lung injury: evaluation of lung injury prediction score in a multicenter cohort study. Am J Respir Crit Care Med 2010;183(4):462-470.

23. Bernard GR, Artigas A, Brigham KL, Carlet J, Falke K, Hudson L, et al. The American-European Consensus Conference on ARDS. Definitions, mechanisms, relevant outcomes, and clinical trial coordination. Am J Respir Crit Care Med 1994;149(3 Pt 1):818-824.
24. Checkley W, Brower R, Korpak A, Thompson BT. Effects of a clinical trial on mechanical ventilation practices in patients with acute lung injury. Am J Respir Crit Care Med 2008;177(11):1215-1222.

25. Netzer G, Liu X, Harris AD, Edelman BB, Hess JR, Shanholtz C, et al. Transfusion practice in the intensive care unit: a 10-year analysis. Transfusion 2010;50(10):2125-2134.

26. Tallach R, Jefferson P, Ball DR. Mechanical ventilation for patients with ARDS: a U.K. survey on calculation of tidal volume. Intensive Care Med 2006;32(1):176.

27. O'Brien JM Jr, Welsh CH, Fish RH, Ancukiewicz M, Kramer AM. Excess body weight is not independently associated with outcome in mechanically ventilated patients with acute lung injury. Ann Intern Med 2004;140(5):338-345.

28. Gong MN, Bajwa EK, Thompson BT, Christiani DC. Body mass index is associated with the development of acute respiratory distress syndrome. Thorax 2010;65(1):44-50.

29. Li G, Malinchoc M, Cartin-Ceba R, Venkata CV, Kor DJ, Peters SG, et al. Eight-year trend of acute respiratory distress syndrome: a population-based study in Olmsted County, Minnesota. Am J Respir Crit Care Med 2011;183(1):59-66.

This article is approved for Continuing Respiratory Care Education credit. For information and to obtain your CRCE

(free to AARC members) visit www.rcjournal.com 